\title{
Article
}

\section{Driving in stroke survivors aged 18-65 years: The Psychosocial Outcomes In StrokE (POISE) Cohort Study}

Yu, S, Muhunthan, J, Lindley, R, Glozier, N, Jan, S, Anderson, C, Li, Q and Hackett, Maree

Available at http://clok.uclan.ac.uk/19604/

Yu, S, Muhunthan, J, Lindley, R, Glozier, N, Jan, S, Anderson, C, Li, Q and Hackett, Maree ORCID: 0000-0003-1211-9087 (2016) Driving in stroke survivors aged 18-65 years: The Psychosocial Outcomes In StrokE (POISE) Cohort Study. International Journal of Stroke, 11 (7). pp. 799-806. ISSN 17474930

It is advisable to refer to the publisher's version if you intend to cite from the work. http://dx.doi.org/10.1177/1747493016641952

For more information about UCLan's research in this area go to http://www.uclan.ac.uk/researchgroups/ and search for <name of research Group>.

For information about Research generally at UCLan please go to http://www.uclan.ac.uk/research/

All outputs in CLoK are protected by Intellectual Property Rights law, including Copyright law. Copyright, IPR and Moral Rights for the works on this site are retained by the individual authors and/or other copyright owners. Terms and conditions for use of this material are defined in the policies page. 
Driving in stroke survivors aged 18-65 years: The Psychosocial Outcomes In StrokE (POISE) Cohort Study

Sungwook $\mathrm{Yu}^{1,2}$, Janani Muhunthan ${ }^{2}$, Richard Lindley ${ }^{2,3}$, Nick Glozier ${ }^{4}$, Stephen Jan ${ }^{2}$, Craig Anderson ${ }^{2}$, Qiang $\mathrm{Li}^{2}$, Maree L. Hackett ${ }^{2,5}$

${ }^{1}$ Department of Neurology, Korea University College of Medicine, Seoul, Republic of Korea

${ }^{2}$ The George Institute for Global Health, University of Sydney and Royal Prince Alfred Hospital, Sydney, New South Wales, Australia,

${ }^{3}$ Westmead Clinical School, University of Sydney, Sydney, New South Wales, Australia ${ }^{4}$ Psychological Medicine, Brain and Mind Centre, Sydney Medical School, University of Sydney, Sydney, New South Wales, Australia,

${ }^{5}$ School of Health, The University of Central Lancashire, Preston, United Kingdom

Key words: stroke, driving, public health, epidemiology

Author for correspondence: A/Prof Maree L. Hackett

The George Institute for Global Health

PO Box M201, Missenden Road, NSW 2050, AUSTRALIA

T: +61-2-9993-4593, F: +61-2-9993-4502, Email: mhackett@georgeinstitute.org.au

Word count: abstract 250; main text 3818

Table 1: Characteristics of participants who were driving before the onset of acute stroke, over 12 months of follow-up

Table 2: Characteristics of participants who returned to driving within one month of acute stroke

Table 3: Multivariable logistic regression model for return to driving within one month of stroke 


\begin{abstract}
Background There is limited information regarding return to driving after stroke.
\end{abstract}

Aims To determine the frequency and predictors of return to driving within one month of acute stroke in younger (age 18 to 65 years) adults.

Methods POISE (Psychosocial Outcomes In StrokE) wais a cohort study conducted in Australia between October 2008 and June 2010. Consecutive patients (age 18 to 65 years) with a recent ( $\leq 28$ days) acute stroke were recruited. Validated demographic, clinical, mental health, cognitive and disability measures including return to driving were obtained.

Multivariate-Multivariable logistic regression was used to determine factors associated with return to driving within one month of stroke.

Results Among 359 participants who were legally able to drive before stroke, 96 (26.7\%) returned to driving within one month. Compared to those without an early return to driving $(n=263)$, drivers were more often male, the main income earner, in paid work before stroke and without symptoms of depression or fatigue. Independence in activities of daily living (odds ratio $[\mathrm{OR}] 30.05,95 \%$ confidence interval [CI] 3.85-234.45), not recalling receiving advice on driving cessation (OR 5.55, 95\% CI 2.86-11.11), and having returned to paid work (OR 3.93, 95\% CI 1.94-7.96) were associated with early return to driving.

Conclusions One in four young adults resumed driving within a month, contrary to guideline recommendations. These data reinforce the importance of deciding who is responsible for determining fitness to drive after stroke, when, and whether it is reasonable to enforce driving restrictions on those with minimal disability who are fit to return to work.

Registration: Australian New Zealand Clinical Trials Registry ANZCTRN 12608000459325 


\section{Introduction}

Acute stroke is a common medical condition which can restrict one's ability to resume driving due to cognitive, visual, or motor disability $(1,2)$. Most people consider driving an important aspect of independent living required to fulfil roles at home and work, and for social, financial and psychological necessity (3). Stroke rates have risen by $25 \%$ in those aged between 20 and 64 years, such that they now account for one third of the global burden of this disease (4). However, the impact of stroke in this age group is seldom described, especially in relation to restrictions on driving. 'Driving is the fifth most common reason to phone the Stroke Foundation of Australia's StrokeLine (5). Generally people are confused and frustrated by a lack of information about how long they shouldn't drive for, the pathway back to driving and alternative transport options' (email exchange with J. Czerenkowski, National Manager Community Programs, November 2015).

Guidelines issued by Australia's National Stroke Foundation (NSF) (6) and Austroads, the association of Australian and New Zealand road transport and traffic authorities (2), recommend that people cease driving for at least one month after acute stroke, or for three months in the case of commercial drivers, and for two weeks following a transient ischaemic attack (TIA), to ensure medical stability and recovery of any deficits. In Australia, drivers have a legal responsibility to report to driving authorities any permanent or long-term injury or illness that may impair their ability to drive safely. In the event of a motor vehicle accident, stroke survivors may not be insured if they do not report their condition, or adhere to advice given to them by health professionals or licensing authorities, and they can be prosecuted if their condition is found to have contributed to the accident (2). Health professionals have a duty to consider breaching patient confidentiality in certain situations to report continued driving to the licensing authority; but in most jurisdictions they are protected from liability if they do so in good faith (2). The guidelines outline key features to be taken into account in this determination in the case of someone who has had a stroke.

Australian guidelines $(2,6)$ recommend that health professionals advise patients against driving for the required time frames. However, less than half of stroke survivors are given such advice and only a small proportion recall the advice given $(1,7,8)$. This may reflect a low level of awareness of current driving guidelines among health professionals $(9,10)$, or avoidance of giving advice $(1,11)$. Irrespective of the advice given, there is evidence indicating that people self-regulate their driving according to how they perceive their fitness 
to drive $(7,12)$, with those experiencing an acute stroke over-estimating their ability to drive (12). Most people are able to resume driving in the first year after stroke (13-15), but the timing of this varies. One third of patients with minor stroke/TIA in the UK (8) and 50\% of those with ischaemic stroke in a hospital-based cohort in US (14) resumed driving within one month after onset. We aimed to provide information on the frequency and determinants of early return to driving after stroke in younger ( $<65$ years) people in Australia.

\section{Methods}

The design of the Psychosocial Outcomes In StrokE (POISE) study has been reported elsewhere $(16,17)$. In brief, POISE was a prospective observational cohort study that included 440 people aged between 18 and 65 years who survived an acute stroke following admission to one of 20 public hospitals in the Stroke Services New South Wales (SSNSW) clinical network in Australia between October 2008 and June 2010. Eligibility for the study included having had an acute stroke within 28 days and being able to speak sufficient English to participate in computer-assisted telephone interviews (or computer-assisted face to face interviews when necessary). All participants or their approved proxy provided informed consent and the study was approved by the Human Research Ethics committee of the Sydney South West Area Health Service.

Baseline demographic and clinical information was collected by clinical staff at each hospital. All participants were assessed at baseline (28 days), six and 12 months after stroke, by trained interviewers based at The George Institute for Global Health who used computerassisted forms. The variables included in these analyses were: driving status (before and after stroke), driving license status, job-related driving, recall being told to stop driving after stroke, level of education, paid employment (full-time, part-time or self-employed), independence from others in activities of daily living (ADL), score in cognitive function according to the Telephone Interview for Cognitive Status (TICS-M) (18), level of function according to instrumental activities of daily living on the Frenchay Activities Index (FAI) scale (19), depressive symptoms according to the depression subscale of the Hospital Anxiety and Depression Scale (HADS-D) (20), and fatigue symptoms according to the vitality domain of the 36-item Short Form questionnaire (SF-36) (21). Information regarding paid and unpaid work was collected using modified versions of questions 34-51 of the Australian Bureau of Statistics 2006 Census and selected questions from the job content questionnaire (JCQ) (22). 
For statistical analyses, the data are expressed as mean ( \pm standard deviation $(\mathrm{SD}))$ or frequency (\%), with comparison between drivers and non-drivers post-stroke assessed using the Chi-Square test or two-sample $t$ tests. Baseline (28 day) variables for which there was an a priori assumption that they might predict return to driving (age, sex, independence in ADL, in paid work, being told to stop driving), and variables that demonstrated a significant association $(\mathrm{p}<0.20)$ with the outcome in bivariate analyses were considered for possible inclusion in multivariable models. Correlation and first order interaction between variables was assessed (none were found). A multivariable logistic regression model was built using all variables significant at $\mathrm{p}<0.20$ in the univariate analyses with adjustment for age. The predictive ability of the model was assessed by area under the curve (AUC). Data are reported with odds ratios (OR) and 95\% confidence intervals (CI). All analyses were conducted using SAS version 9.3.

\section{Results}

There were 359 (82\%) participants who were driving before the onset of stroke. Those not driving before their stroke were less likely to be married or in a de facto relationship, in fulltime work, have health insurance and were more likely to have a pre-morbid illness that restricted their activities (data available on request).

The characteristics of included participants are presented in Table 1. Participants had an average age of $52( \pm 10)$ years, most $(67 \%)$ were employed in full or part time work and had an ischaemic stroke (83\%). $86 \%$ Eighty-six percent of participants in paid work drove to work by car.

Within one month of stroke, 96 (26.7\%) participants had returned to driving and $301(83.8 \%)$ had driven at least once by 12 months. Among the 96 participants who returned to driving within one month, 38 (40\%) had also returned to paid work, 43 (45\%) did not recall being told to stop driving, and 14 (15\%) were considered cognitively impaired on the TICS-M screening tool (Table 2). Of the 14 with cognitive impairment, eight (57\%) did not recall being told to stop driving.

Compared to participants who did not return to driving within one month, those who drove were significantly more likely to be male, the main income earner in their household, to be independent in ADL and to have returned to paid work. They were less likely to be 
depressed, fatigued, and able to recall being told to stop driving (Table 2). No differences were found in other baseline characteristics.

In the multivariablete model, participants were more likely to return to driving within one month of stroke if they were independent in activities of daily living at 28 days (OR 30.05, 95\% CI 3.85 to 234.45), did not recall being told to stop driving (OR 5.55, 95\% CI 2.86 to 11.11), and had returned to paid work (OR 3.93, 95\% CI 1.94 to 7.96, Table 3). The AUC for this model was 0.816 .

Compared to participants who drove in the 12 months after stroke, the $58(16 \%)$ who never drove were significantly more likely at baseline to be female, single, smoke, have an activityrestricting illness, other illnesses, a history of depression, to be depressed and to experience fatigue. Non-driving participants were less likely to have post-school qualifications, be the main income earner in the household, work in their own business or to have health or income insurance at the time of their stroke. At 28 days after stroke, non-driving participants were more likely to be dependent on others for their activities of daily living, less likely to recall being told to stop driving, and less likely to be cognitively competent. We did not conduct multivariable modelling due to the small number of participants and the large number of associated variables.

\section{Discussion}

In this study, approximately one quarter of younger adults had returned to driving within one month of stroke, contrary to Australian policy and guideline recommendations (6) and despite more than half having been advised against doing so. Similar to research showing minimal disability predicts return to driving within six months, our early driving population tended to be without major residual disability as defined by independence in $\operatorname{ADL}(12,14,23)$. This is in contrast to those who did not drive at all in the first year after stroke who were more likely to be female, have risk factors for stroke and comorbidity (including being dependent one month after stroke), and less likely to have health or income insurance.

Of note is the finding that those who had returned to work were four times more likely to drive within one month. Since driving a car was the most common way to travel to work in our study population, it is possible that early return to work is leading to early resumption of driving. Given the disparities in access to public transport across urban and suburban areas in 
Australia, survivors of stroke may be driving early (despite advice to the contrary) in order to maintain job security due to issues with the availability or affordability of alternative means of transport such as taxi subsidy schemes. Not all rural and regional locations in Australia have an accessible taxi service. In locations where government-funded subsidies are operational, such as the NSW Taxi Transport Subsidy Scheme (TTSS), an applicants' health condition must meet a high threshold of severity, for instance being unable to walk or stand or being mobile outside of home only with a wheelchair due to physical disability, in order to be eligible. An additional difficulty for survivors of stroke is that eligibility requirements and subsidies offered (a maximum of \$30 per trip for NSW's TTSS) are not uniform across all states and territories. Therefore, the challenge of finding alternate accessible transport options may also contribute to early resumption to driving.

Depression has been associated with the cessation of driving after acute stroke $(13,24)$. Enforced driving cessation can result in a loss of mobility leading to reduced social activities and increased depression. In our study, those who returned to driving were less likely to experience depression or fatigue. Cognition is known to affect the ability to drive after stroke $(15,23)$. Of concern, was the finding that $15 \%$ of those people who had resumed driving were considered to be cognitively impaired on objective testing, although there was no direct assessment of cognitive and/or driving ability.

Although over half of people who returned to driving within one month recalled being given advice not to drive, this did not seem to impact on driving resumption. Health professionals have an important role in advising stroke survivors of the consequences of their medical condition or ability to drive, as well as recommending restrictions and ongoing monitoring (2, 6). All POISE participants were admitted to a stroke unit with medical (neurologist, geriatrician and/or rehabilitation physician), nursing and allied health staff (occupational therapist, physiotherapist, speech therapist, neuropsychologist, social worker, and dietician). It is possible that staff are unclear about who is responsible for discussing or evaluating fitness to drive, and when this should occur. While some may consider it the job of rehabilitation physicians (10), they are unlikely to see patients with minimal or no disability (who are generally discharged directly home from the acute stroke unit) and referral of these patients may be considered unnecessary and time consuming. Reasons for stroke unit staff not advising patients about the driving rules will include uncertainty about the current guidelines, a belief that another health professional would be doing this task, or error. 
General practitioners have reported discomfort in assessing fitness to drive, despite the Guidelines clearly stating that GPs have an important role in this duty, due to the potential consequences for their patients, such as a reluctance to give up their licence (11) and its association with social isolation. In addition, assessing fitness to drive may compromise the doctor-patient relationship_(25), expose unclear medico-legal responsibilities $(25,26)$ and poor knowledge of the content of current guidelines (26). One Australian study showed that only $53 \%$ of general practitioners were confident in their ability to evaluate fitness to drive in their patients (25), another found that $74 \%$ wanted further education to assess fitness-to-drive and $71 \%$ on legal obligations (25).

It seems logical that assessment of fitness to drive for those with minimal or no disability after stroke should be a collaborative effort between medical and allied health staff prior to discharge from hospital. There are valid office-based tools available to help with assessment (the Road Side Recognition and Compass components of the Stroke Drivers Screening Assessment (27); Trail Making Test part B(28)) (29) as on-road driving tests are costly, time consuming, and in the case of the minimally impaired, unnecessary. Ideally, the post admission follow-up should be timed for about a month to ensure that those discharged with any disability are checked to ensure no important stroke impairments remain.

For stroke patients with obvious limitations concerning driving, in South Australia and the Northern Territory, health professionals (as defined by state legislation) are the subject of unique mandatory reporting requirements. These provide that where they believe a driver is physically or mentally unfit to drive, they must notify the relevant authority. In all other states, health professionals have more flexibility and can, as required, give supporting evidence for a conditional license or refer stroke survivors for a driver assessment. In addition, as an exception to professional and legal obligations to maintain confidentiality, if health professionals in good faith choose to notify licensing authorities that a patient is unfit to drive, or that it may be dangerous to allow them to hold, be issued or have renewed a driver's licence, they are protected from civil or criminal liability (2).

We did not collect information on fitness to drive, traffic accidents or verify the receipt or quality of driving advice in our study. Therefore, to whether stroke sumivors who retmed to driving were safe drivers or reecived proper adviee. However, the substantial number of younger stroke survivors driving within one month of stroke suggests potential deficiencies and medico-legal issues regardless of fitness to drive or 
quality of advice. Most stroke survivors returned to driving after the one month stand-down period and within six months of stroke. However, Therefore, we could not draw observations as to whether any stroke survivors who returned to driving were safe drivers or received proper advice. We recommend that all patients admitted with stroke are asked whether they are current driving license holders and, at discharge ensure that the patient has been advised appropriately. 


\section{References}

1. Hawley CA. The Attitudes of Health Professionals to Giving Advice on Fitness to Drive. London: Department for Transport, 2010.

2. Austroads. Assessing fitness to drive- [cited Feb-Nov 20142015]. Available from: http://www.austroads.com.au/drivers-vehicles/assessing-fitness-to-drive http://www.austroads.com.au/images/stories/assessing_fitness_to_drive_2013_rev2.pdf.

3. Reed M, Harrington R, Duggan A, Wood VA. Meeting stroke survivors' perceived needs: a qualitative study of a community-based exercise and education scheme. Clin Rehabil. 2010 Jan;24(1):16-25.

4. Feigin VL, Forouzanfar MH, Krishnamurthi R, Mensah GA, Connor M, Bennett DA, et al. Global and regional burden of stroke during 1990-2010: findings from the Global Burden of Disease Study 2010. Lancet. 2014 Jan 18;383(9913):245-54. PubMed PMID: 24449944.

5. Stroke Foundation (Australia). StrokeLine 2015 [cited 2015]. Available from: https://strokefoundation.com.au/about-stroke/help-after-stroke/strokeline.

6. National Stroke Foundation. Clinical guidelines for stroke management Melbourne Australia 2010. Available from:

https://strokefoundation.com.au/ /media/strokewebsite/resources/treatment/clinicalguidelines-acute-rehab-management-2010-interactive.ashx?la=en .

7. Fisk GD, Owsley C, Pulley LV. Driving after stroke: driving exposure, advice, and evaluations. Arch Phys Med Rehabil. 1997 Dec;78(12):1338-45.

8. McCarron MO, Loftus AM, McCarron P. Driving after a transient ischaemic attack or minor stroke. Emerg Med J. 2008 Jun;25(6):358-9.

9. Kelly R, Warke T, Steele I. Medical restrictions to driving: the awareness of patients and doctors. Postgrad Med J. 1999 Sep;75(887):537-9. 
10. Allen ZA, Halbert J, Huang L. Driving assessment and rehabilitation after stroke. Med J Aust. 2007;187(10):599.

11. White JH, Miller B, Magin P, Attia J, Sturm J, Pollack M. Access and participation in the community: a prospective qualitative study of driving post-stroke. Disabil Rehabil. 2012;34(10):831-8.

12. Finestone HM, Marshall SC, Rozenberg D, Moussa RC, Hunt L, Greene-Finestone LS. Differences between poststroke drivers and nondrivers: demographic characteristics, medical status, and transportation use. Am J Phys Med Rehabil. 2009;88(11):904-23.

13. Legh-Smith J, Wade DT, Hewer RL. Driving after a stroke. J R Soc Med. 1986 Apr;79(4):200-3.

14. Lee N, Tracy J, Bohannon RW, Ahlquist M. Driving resumption and its predictors after stroke. Conn Med. 2003 Aug;67(7):387-91.

15. Perrier MJ, Korner-Bitensky N, Mayo NE. Patient factors associated with return to driving poststroke: findings from a multicenter cohort study. Arch Phys Med Rehabil. 2010 Jun;91(6):868-73.

16. Hackett ML, Glozier N, Jan S, Lindley R. Psychosocial Outcomes in StrokE: the POISE observational stroke study protocol. BMC Neurol. 2009;9(24):doi:10.1186/471-23779-24.

17. Hackett ML, Glozier N, Jan S, Lindley R. Returning to paid employment after stroke: the Psychosocial Outcomes In StrokE (POISE) cohort study. PLoS One. 2012;7(7):e41795. doi:10.1371/journal.pone.0041795.

18. de Jager CA, Budge MM, Clarke R. Utility of TICS-M for the assessment of cognitive function in older adults. Int J Geriatr Psychiatry. 2003 Apr;18(4):318-24. 
19. Wade DT, Legh-Smith J, Langton Hewer R. Social activities after stroke: measurement and natural history using the Frenchay Activities Index. Int Rehabil Med. 1985;7(4):176-81.

20. Zigmond AS, Snaith RP. The hospital anxiety and depression scale. Acta Psychiatr Scand. 1983 Jun;67(6):361-70.

21. Ware JE SK, Kosinski M, Gandek B. SF-36 health survey: manual and interpretation guide. Boston, MA: New England Medical Center, Health Institute; 1993.

22. Karasek R, Brisson C, Kawakami N, Houtman I, Bongers P, Amick B. The Job Content Questionnaire (JCQ): an instrument for internationally comparative assessments of psychosocial job characteristics. J Occup Health Psychol. 1998 Oct;3(4):322-55.

23. Aufman EL, Bland MD, Barco PP, Carr DB, Lang CE. Predictors of return to driving after stroke. Am J Phys Med Rehabil. 2013;92(7):627-34.

24. Devos H, Akinwuntan AE, Nieuwboer A, Ringoot I, Van Berghen K, Tant M, et al. Effect of simulator training on fitness-to-drive after stroke: a 5-year follow-up of a randomized controlled trial. Neurorehabil Neural Repair. 2010;24(9):843-50.

25. Sims J, Rouse-Watson S, Schattner P, Beveridge A, Jones KM. To Drive or Not to Drive: Assessment Dilemmas for GPs. Int J Family Med. 2012;2012:417512.

26. Shanahan EM, Sladek RM, Phillips P. Medical aspects of fitness to drive. What do public hospital doctors know and think? Intern Med J. 2007 Jun;37(6):372-6.

27. Lincoln NB, Radford KA, Nouri FM. Stroke Drivers' Screening Assessment Australian Version Manual. University of Nottingham 2011.

28. Reitan RM. Validity of the Trail Making test as an indicator of organic brain damage. Perceptual and Motor Skills. 1958;8:271-6. 
29. Devos H, Akinwuntan AE, Nieuwboer A, Truijen S, Tant M, De Weerdt W.

Screening for fitness to drive after stroke: a systematic review and meta-analysis. Neurology. 2011;76:747-56. 
Table 1 Characteristics of participants who were driving before the onset of acute stroke, over 12 months of follow-up

\begin{tabular}{cccc}
\hline & \multicolumn{3}{c}{ Period post-stroke } \\
\cline { 2 - 4 } & 1 month & 6 months & 12 months \\
$(\mathrm{n}=359)$ & $(\mathrm{n}=352)$ & $(\mathrm{n}=341)$ & \\
\hline
\end{tabular}

\section{Pre-stroke}

Driving was a requirement of their job*

$122 / 242(50.4)$

\section{Post-stroke}

Independent in activities of daily living

$\begin{array}{ccc}355 / 359(98.9) & 313 / 351(89.2) & 304 / 341(89.2) \\ 273 / 327(83.5) & 283 / 327(86.5) & 278 / 315(88.3) \\ 282 / 327(86.2) & 283 / 327(86.5) & 276 / 313(88.2) \\ 38.8(18.9) & 53.5(25.9) & 56.3(26.0) \\ & 287 / 351(81.8) & 283 / 341(83.0) \\ 96 / 359(26.7) & 254 / 351(72.4) & 263 / 340(77.1) \\ 68 / 242(28.1) & 168 / 236(71.2) & 168 / 231(72.7) \\ 252 / 356(70.8) & 18 / 254(7.1) & 36 / 338(10.7) \\ 217 / 252(86.1) & 13 / 18(72.2) & 24 / 36(66.7) \\ 32 / 252(12.7) & 3 / 18(16.7) & 1 / 36(2.8) \\ & 1 / 18(5.6) & \end{array}$

By police

$5 / 252(2.0)$

By a family member

$11 / 252(4.4)$

2/18 (11.1)

10/36 (27.8) 
Return to driving against advice since last assessment $53 / 252(21.0)$

$18 / 18(100.0)$

$4 / 36(11.1)$

Numbers are frequency (\%) unless otherwise specified;

*Denominator indicative of those who were in paid employment before stroke

HADS-D, score on the depression subscale of the Hospital Anxiety and Depression Scale; SD, standard deviation; SF-36 vitality, vitality domain score of the 36 item Short Form 
Table 2 Characteristics of participants who returned to driving within one month of acute stroke

\begin{tabular}{|c|c|c|c|c|c|}
\hline & \multicolumn{2}{|c|}{ Returned to driving } & \multirow[b]{2}{*}{ OR } & \multirow[b]{2}{*}{$95 \% \mathrm{CI}$} & \multirow[b]{2}{*}{ P Value } \\
\hline & $\begin{array}{c}\text { Yes } \\
(n=96)\end{array}$ & $\begin{array}{c}\text { No } \\
(n=263)\end{array}$ & & & \\
\hline \multicolumn{6}{|l|}{ Pre-stroke } \\
\hline Age (years), mean (SD) & $53.4(9.1)$ & $51.9(10.3)$ & 1.02 & $0.99-1.04$ & 0.23 \\
\hline Male & $74 / 96(77.1)$ & $168 / 263(63.9)$ & 1.90 & $1.11-3.26$ & 0.02 \\
\hline \multicolumn{6}{|l|}{ Education } \\
\hline School certificate or less & $40 / 95(42.1)$ & $90 / 263(34.2)$ & Ref. & & \\
\hline $\mathrm{HSC} /$ trade certificate & $19 / 95(20.0)$ & $76 / 263(28.9)$ & 0.56 & $0.30-1.05$ & 0.09 \\
\hline Diploma/degree & $36 / 95(37.9)$ & 97/263 (36.9) & 0.84 & $0.49-1.42$ & 0.67 \\
\hline \multicolumn{6}{|l|}{ Marital status (partner) } \\
\hline Never married & $10 / 96(10.4)$ & $34 / 263(12.9)$ & Ref. & & \\
\hline Married/de facto & $20 / 96(20.8)$ & $56 / 263(21.3)$ & 1.30 & $0.61-2.77$ & 0.54 \\
\hline Other & $66 / 96(68.8)$ & $173 / 263(65.8)$ & 1.21 & $0.51-2.90$ & 0.84 \\
\hline Lives in rural area & $19 / 96(19.8)$ & 45/263 (17.1) & 1.20 & $0.66-2.17$ & 0.56 \\
\hline Lives with others & $82 / 96(85.4)$ & $219 / 263(83.3)$ & 1.18 & $0.61-2.26$ & 0.63 \\
\hline Number of financially dependent children, mean $( \pm$ SD) & $0.6(0.9)$ & $0.7(1.1)$ & 0.95 & $0.75-1.20$ & 0.65 \\
\hline Main income earner & $69 / 95(72.6)$ & $140 / 259(54.1)$ & 2.26 & $1.35-3.77$ & 0.002 \\
\hline Non-smoker & $53 / 95(55.8)$ & $153 / 263(58.2)$ & 0.91 & $0.57-1.46$ & 0.69 \\
\hline No illness that restricted activity & $72 / 95(75.8)$ & $212 / 263(80.6)$ & 0.75 & $0.43-1.32$ & 0.32 \\
\hline
\end{tabular}


No other comorbid illnesses

No history of depression

Frenchay Activities Index, mean (SD)

Low (0 to 15 )

Moderate (16 to 30 )

High (31 to 45)

\section{Work}

Worked full-time or part-time

Self-employed/own business

No health insurance

No income protection insurance

Years in current job, mean $( \pm \mathrm{SD})$

Driving was a requirement of their job before stroke

\section{8 days post-stroke}

Independent in activities of daily living

Cognitively competent

Not depressed (HADS-D score <8)

Fatigue (SF-36 vitality score), mean (SD)

Did not recall being told to stop driving
Returned to paid work

\begin{tabular}{|c|c|c|c|c|}
\hline 46/95 (48.4) & $139 / 263(52.9)$ & 0.84 & $0.52-1.34$ & 0.46 \\
\hline 68/96 (70.8) & $160 / 263(60.8)$ & 1.56 & $0.94-2.59$ & 0.08 \\
\hline $30.9(6.5)$ & $31.5(6.7)$ & 0.99 & $0.95-1.02$ & 0.48 \\
\hline $3 / 96(3.1)$ & $7 / 263(2.7)$ & Ref. & & \\
\hline $36 / 96(37.5)$ & $92 / 263(35.0)$ & 0.91 & $0.22-3.73$ & 0.97 \\
\hline $57 / 96(59.4)$ & $164 / 263(62.4)$ & 0.81 & $0.20-3.24$ & 0.67 \\
\hline $73 / 96$ (76.1) & $169 / 263(64.3)$ & 1.77 & $1.04-3.01$ & 0.04 \\
\hline $20 / 45$ (44.4) & $40 / 112(35.7)$ & 1.44 & $0.71-2.91$ & 0.31 \\
\hline 47/94 (50.0) & $135 / 263(51.3)$ & 0.95 & $0.59-1.52$ & 0.82 \\
\hline 79/95 (83.2) & $237 / 263(90.1)$ & 0.54 & $0.28-1.06$ & 0.07 \\
\hline $12.7(11.2)$ & $11.3(11.8)$ & 1.01 & $0.99-1.03$ & 0.32 \\
\hline $38 / 71$ (53.2) & $84 / 169(49.0)$ & 1.17 & $0.67-2.03$ & 0.59 \\
\hline 92/94 (97.9) & $181 / 246(73.6)$ & 16.52 & $3.96-68.98$ & $<0.001$ \\
\hline $79 / 93$ (85.0) & $194 / 234(82.9)$ & 1.16 & $0.60-2.26$ & 0.65 \\
\hline 87/93 (93.6) & $195 / 234(83.3)$ & 2.90 & $1.18-7.10$ & 0.02 \\
\hline 43.4 (19.7) & $37.0(18.3)$ & 1.02 & $1.01-1.03$ & 0.005 \\
\hline 43/96 (44.8) & $61 / 260(23.5)$ & 2.63 & $1.61-4.35$ & $<0.001$ \\
\hline 38/96 (39.6) & $30 / 263(11.4)$ & 5.09 & $2.91-8.89$ & $<0.001$ \\
\hline
\end{tabular}

Numbers are frequency $(\%)$ unless otherwise specified 
HADS-D, score on depression subscale of the Hospital Anxiety and Depression Scale; SD, standard deviation; SF-36 vitality, vital domain score on the Short Form 36 item questionnaire; OR, odds ratio; CI, confidence interval 
Table 3 Multivariable logistic regression model for return to driving within one month of stroke

\begin{tabular}{lccc}
\hline & \multicolumn{3}{c}{ Multivariable analysis } \\
\cline { 2 - 3 } & OR & $95 \%$ CI & P value \\
\hline Pre-stroke & 1.02 & $0.99-1.06$ & 0.20 \\
Age & 1.22 & $0.62-2.44$ & 0.57 \\
Male & & & \\
Education & Ref. & & 0.08 \\
School certificate or less & 0.50 & $0.23-1.09$ & 0.13 \\
HSC/trade certificate & 0.59 & $0.30-1.17$ & 0.39 \\
Diploma/degree & 1.35 & $0.68-2.69$ & 0.31 \\
Main income earner & 1.41 & $0.73-2.71$ & 0.30 \\
No history of depression & 1.53 & $0.68-3.42$ & 0.93 \\
Worked full-time or part-time & 0.96 & $0.39-2.36$ & \\
No income protection insurance & & & $<0.001$ \\
$\mathbf{2 8}$ days post-stroke & & & $<.001$ \\
Independent in activities of daily living & 30.05 & $3.85-234.45$ & 0.001 \\
Not depressed (HADS-D score <8) & 1.44 & $0.50-4.15$ & 0.50 \\
Fatigue (SF-36 vitality score) & 1.00 & $0.99-1.02$ & 0.77 \\
Did not recall being told to stop driving & 5.55 & $2.86-11.11$ & $1.94-7.96$ \\
Returned to paid work & 3.93 & & \\
\hline
\end{tabular}

HADS-D, score on the depression subscale of the Hospital Anxiety and Depression Scale; SF36 vitality, vitality domain score on the 36 item Short Form questionnaire; OR, odds ratio; CI, confidence interval 